\title{
Predicados de gosto pessoal em português brasileiro: individual ou stage level predicates?
}

\section{Personal taste predicates in Brazilian Portuguese: individual or stage level predicates?}

\author{
Marina Nishimoto Marques \\ Renato Miguel Basso*
}

Resumo

Em seu trabalho A Judge-Free Semantics for Predicates of Personal Taste, Pearson (2012) propõe uma abordagem semântica para os chamados predicados de gosto pessoal (PGP) e os problemas trazidos por eles. Um dos principais pilares de sua proposta é considerar que os PGPs pertençam ao grupo dos individual level predicates (ILP), ou seja, predicados que expressam características inerentes ao indivíduo com o qual se combinam, em oposição aos stage level predicates (SLP), que expressam características transitórias do indivíduo com o qual se combinam. Um exemplo de ILP seria "alto", enquanto um de SLP seria "doente". Para demonstrar que os predicados de gosto são de fato ILPs, a autora apresenta uma série de testes que, segundo ela, comprovam que esses predicados se comportam como os ILPs. Todos os testes apresentados são realizados em inglês e funcionam nessa língua. No entanto, ao tentarmos reproduzir os mesmos testes em português brasileiro (PB), vemos que eles não funcionam tão bem, ou seja, parece que os PGPs em PB não se comportam exatamente como os ILPs, como Pearson havia afirmado. Uma possível razão que explica o não-funcionamento dos testes em PB é a diferenciação entre "ser" e "estar" que esta língua apresenta e que o inglês não, algo que interfere bastante nos exemplos trazidos por Pearson para a realização dos testes. Nossa proposta, então, é analisar se os PGPs são realmente ILPs como diz a autora, desta vez para uma língua como o PB, o que significa reavaliar os testes propostos ou propor outros mais adequados.

Palavras-chave: Predicados de gosto. Individual level predicates. Semântica.

\footnotetext{
* UFSCar. Agradecemos ao apoio da FAPESP, processo 2014/17359-4.

${ }^{\star \star}$ UFSCar/CNPq
} 
M. N. Marques

$\&$ R. M. BASSO Predicados de gosto pessoal em português brasileiro: individual ou stage level predicates?

\begin{abstract}
In her work 'A judge-free semantics for predicates of personal taste', Pearson (2012) proposes a semantic approach for the so-called predicates of personal taste (PPT) and the problems they bring. One of the main pillars of her proposal is to take into consideration that PPTs are part of the group of the individual level predicates (ILP), i.e. predicates that express characteristics that are inherent to the individual they combine with, as opposed to stage level predicates (SLP), which express transitory characteristics of the individuals they combine with. An example of ILP would be 'tall', while an example of a SLP would be 'sick'. To show that PPTs are indeed ILPs, the author presents a series of tests that, according to her, prove that these predicates behave like the ILPs. All of Pearson's tests work in English. However, if we try to reproduce the same tests in Brazilian Portuguese (BP), we see that they do not behave exactly like ILPs, as Pearson had proposed. A possible reason that explains the malfunctioning of the tests in BP is the difference between 'ser' and 'estar', which BP presents and English does not. This fact interferes with the examples brought by Pearson for the accomplishment of the tests. Therefore, our proposal is to analyse if PPTs are indeed ILPs as the author claims, but this time regarding a language like Brazilian Portuguese. This means reevaluate the proposed tests or come up with more adequate ones.
\end{abstract}

Key words: Predicates of personal taste. Individual level predicates. Semantics.
Revista Letras, Curitiba, UfPr, n. 96, pp.132-151, jul./dez. 2017. ISSN 2236-0999 (versão eletrônica) 


\section{Introdução}

$134 \longrightarrow \mathrm{m}$ seu trabalho Context dependence, disagreement, and predicates of personal taste, Lasersohn (2005) chama a atenção para um tipo de predicado que o autor denomina predicates of personal taste, ou "predicados de gosto pessoal” (PGPs). Para o autor, o problema desses predicados seria o de gerar, entre os falantes, desacordos nos quais um nega diretamente o que o outro fala e, no entanto, ninguém está proferindo algo falso - tal fenômeno é chamado de faultless disagreement. Esse fenômeno pode ser ilustrado pelo exemplo em (1), que contém o PGP "gostoso":

(1) Ana: Esse bolo é gostoso.

Beatriz: Não, esse bolo não é gostoso.

Como se pode observar, intuitivamente, embora uma falante negue diretamente o que outra falante diz, nenhuma das duas está afirmando algo falso. Isso não ocorre quando nos deparamos com diálogos envolvendo afirmações sobre fatos objetivos:

(2) Amanda: Tóquio é a capital do Japão.

Bárbara: Não, Tóquio não é a capital do Japão. 
M. N. Marques

\& R. M. Basso Predicados de gosto pessoal em português brasileiro: individual on stage level predicates?
No diálogo em (2), diferentemente do que ocorre em (1), não é possível que as duas sentenças proferidas sejam verdadeiras ao mesmo tempo.

O faultless disagreement já era um fenômeno estudado anteriormente, porém relacionado a outros tipos de predicado, os chamados "predicados vagos". Um faultless disagreement contendo um predicado vago está exemplificados em (3):

(3) Aline: Miguel é alto.

Bianca: Não, Miguel não é alto.

Apesar dessa similaridade, "alto" não poderia ser classificado como um PGP, dado que os PGPs se baseiam totalmente na subjetividade do indivíduo a quem o predicado se aplica, ao passo que um predicado vago como "alto", embora contenha certa subjetividade, envolve fatos objetivos em princípio verificáveis. Isso pode ser claramente explicitado se colocarmos esses itens em estruturas de comparação (FLEISHER, 2013), como nos exemplos abaixo:

(4) Andreia: Sorvete é mais gostoso que bolo.

Bruna: Não, sorvete não é mais gostoso que bolo.

(5) Andreia: Miguel é mais alto que Gabriel.

Bruna: Não, Miguel não é mais alto que Gabriel.

No diálogo em (4), que apresenta o PGP "gostoso", a discordância entre as sentenças com estruturas de comparação permanece subjetiva e, portanto, o fenômeno do faultless disagreement se mantém. Por outro lado, em (5), o exemplo que traz o predicado vago "alto", o faultless disagreement não ocorre, já que, como não ocorre em (4), é possível que se apure objetivamente qual das duas falantes está correta, e não há como as duas sentenças proferidas serem simultaneamente consideradas verdadeiras sem que haja uma contradição.

Assim, os PGPs, embora apresentem certas semelhanças com os predicados vagos, funcionam de modo diferente em alguns aspectos e, portanto, precisam de um tratamento diferente daquele dado aos predicados vagos.

Dentre as propostas encontradas na literatura para lidar com os PGPs, neste trabalho, focaremos na abordagem proposta por Pearson (2012); mais especificamente, investigaremos, usando dados do PB, uma das bases da proposta da autora, a saber, PGPs são ILPs. Para isso, começaremos, na seção 1, falando sobre a abordagem apresentada por Pearson (2012), destacando por que é importante para sua teoria que PGPs sejam classificados como ILPs, e como a autora argumenta a favor desse fato, assim como as limitações desses argumentos. Na seção 2, exploramos três possibilidades de classificação para os PGPs, argumentando contra duas delas e a favor de uma. Por fim, na seção
Revista Letras,

Curitiba, UFPR, n. 96, pp.132-151, jul./dez. 2017. ISSN 2236-0999 (versão eletrônica) 
3, propomos uma solução para uma questão deixada em aberto em relação à classificação dos PGPs em ILPs e sua combinação com os verbos de ligação do PB.

\section{A proposta de Pearson (2012)}

Em seu trabalho $A$ judge-free semantics for predicates of personal taste, Pearson (2012) irá propor que "Predicados de gosto pessoal como gostoso são usados para fazer afirmações sobre a possibilidade de algo ser gostoso para as pessoas em geral, baseada em experiência pessoal" (PEARSON, 2012, p. 15, tradução nossa). Ou seja, para a autora, quando alguém profere uma sentença como "Esse bolo é gostoso", duas condições são cumpridas: (i) o falante se compromete com a opinião de que o bolo é gostoso e (ii) ele também está generalizando (baseado em sua própria experiência) a experiência de o bolo ser gostoso para qualquer pessoa com quem ele tenha empatia, que tenha gostos semelhantes aos dele; isto é, Pearson (2012) postula que PGPs são interpretados genericamente. Tendo isso em vista, a formalização proposta por Pearson (2012) para os predicados de gosto pessoal leva em conta diversos elementos que Chierchia (1995) propõe para a análise dos individual level predicates (ILPs). Assim, para entender a proposta de Pearson (2012), é necessário considerar, antes, o que fala o autor sobre esses tipos de predicado.

Segundo Chierchia (1995), ILPs já trazem em sua estrutura formal o operadorgenérico GEN, que funciona como um operador que amarra oargumento davidsoniano que atua sobre os mundos. A estrutura e a interpretação de uma sentença como "João é alto", segundo essa leitura, se dariam, respectivamente, da seguinte forma (PEARSON, 2012, p. 20):

(6a) $\left[\right.$ João $_{i}\left[\right.$ GEN $\left[t_{i}\right.$ é alto $\left.\left.]\right]\right]$

(6b) $\forall w^{\prime}\left[\operatorname{Acc}\left(w, w^{\prime}\right) \wedge A\left(J o a ̃ o, w^{\prime}\right)\right] \quad\left[\operatorname{alto(João,w^{\prime })}\right]$ em que (i) para quaisquer dois mundos possíveis $w, w^{\prime}, \operatorname{Acc}\left(w, w^{\prime}\right)$ sse w'é acessível de w e (ii) para qualquer indivíduo x e mundo w, C(x,w) sse w é habitado por x e x é relevante em w.

A fórmula em (6b) pode ser parafraseada como: em todo mundo possível w', que é acessível de w, tal que João é relevante em w', João é alto.

Dessa forma, notamos as razões por trás da necessidade de PGPs serem ILPs para Pearson (2012): caso PGPs sejam, de fato, ILPs, a partir desse fato a autora conseguiria introduzir a interpretação genérica na formalização desses predicados baseando-se na formalização proposta por Chierchia (1995), que já apresenta um operador genérico GEN em sua composição - ou seja, haveria argumentos independentes de sua proposta para sustentar que PGPs, sendo ILPs, 
M. N. Marques

$\&$ R. M. BASSO

Predicados de

gosto pessoal em português

brasileiro:

individual ou

stage level

predicates? são genéricos. Nessa leitura, a estrutura e a interpretação da sentença "Esse bolo é gostoso" ficariam como em (7a) e (7b), respectivamente (PEARSON, 2012, p. 20):

(7a) $\left[\right.$ Esse bolo $_{i}\left[\right.$ GEN $\left[t_{i}\right.$ é gostoso $\lambda x$. I(falante, $\left.\left.\left.\left.x\right)\right]\right]\right]$

(7b) $\forall \mathrm{x}, \mathrm{w}^{\prime}\left[\mathrm{Acc}\left(\mathrm{w}, \mathrm{w}^{\prime}\right) \wedge \mathrm{C}_{3}\left(\right.\right.$ esse bolo, $\left.\mathrm{x}, \mathrm{w}^{\prime}\right) \wedge \mathrm{I}($ falante, $\left.\mathrm{x})\right]$ [gostoso(esse bolo, $\left.\left.\mathrm{x}, \mathrm{w}^{\prime}\right)\right]^{1,2}$

em que para qualquer mundo w' e qualquer indivíduo $x$, sendo que (i) w' é acessível de w, (ii) esse bolo e x são indivíduos relevantes no mundo w' e (iii) o falante se identifica com o indivíduo x, esse bolo é gostoso para $\mathrm{x}$ em w'.

A interpretação em (7b) pode ser parafraseada da seguinte forma: para todos os mundos w', acessíveis de $\mathrm{w}$, e todos os indivíduos $\mathrm{x}$ tal que (i) w' é habitado por esse bolo e x, (ii) esse bolo e x são relevantes em w', e (iii) o falante se identifica com x, esse bolo é gostoso para x em w'.

Assim, podemos perceber que é central para a teoria de Pearson (2012) que PGPs sejam classificados como ILPs, já que, caso não fossem, a formalização da autora não se sustentaria e a leitura genérica teria que ser introduzida na formalização desses predicados de outra maneira, tornando a computação semântica menos econômica. Para defender essa ideia, a autora apresenta quatro testes nos quais ela utiliza estruturas paralelas com ILPs e SLPs, e compara o comportamento desses itens ao comportamento de PGPs colocados nas mesmas estruturas. Mostrando que os PGPs se comportam de forma semelhante aos ILPs, Pearson (2012) consegue mostrar que eles deveriam ser classificados como ILPs e, portanto, que sua proposta de formalização é pertinente.

No entanto, os testes propostos por Pearson (2012) são pensados para o inglês e não funcionam para o português brasileiro (PB), dado que as estruturas que evidenciam os comportamentos similares dos PGPs e dos ILPs (e a distância dos PGPs em relação aos stage level predicates (SLPs)) não encontram em PB uma correspondência ideal para a aplicação dos testes. Um exemplo de teste em que isso ocorre é o teste que traz as construções existenciais com there:

\footnotetext{
1 Na fórmula, "I(x,y)" é a relação de identidade.

2 Na realidade, a fórmula em (7b) não é a fórmula final usada na teoria de Pearson (2012). Em seu trabalho, a autora propõe que se substitua a fórmula em (7b) pela seguinte fórmula: $\lambda \mathrm{w} \lambda \mathrm{y} . \forall \mathrm{x}, \mathrm{w}^{\prime}\left[\mathrm{Acc}\left(\mathrm{w}, \mathrm{w}^{\prime}\right) \wedge \mathrm{C} 3\left(\right.\right.$ esse bolo, $\left.\left.\mathrm{x}, \mathrm{w}^{\prime}\right) \wedge \mathrm{I}(\mathrm{y}, \mathrm{x})\right]$ [gostoso(esse bolo, $\left.\left.\mathrm{x}, \mathrm{w}^{\prime}\right)\right]$. Isso ocorre porque, no decorrer da defesa de sua abordagem, Pearson (2012) se depara com o problema de tratar PGPs que estejam em sentenças encaixadas. A solução da autora para que se possa derivar a mesma interpretação de sentenças matriz e de sentenças encaixadas é a proposta de que sentenças expressam propriedades, e não valores de verdade, como ocorre na fórmula em (7b). Para efeitos de simplificação, e tendo em vista que não trataremos do problema de PGPs em sentenças encaixadas neste trabalho, não utilizaremos a fórmula final proposta por Pearson, já que a fórmula intermediária apresentada em (7b) corresponde mais proximamente à fórmula para o ILP "alto" de Chierchia (1995) apresentada em (6b) e, dessa forma, o paralelo entre as duas formalizações fica mais claro.
}

Revista Letras,

Curitiba, UFPR, n. 96, pp.132-151, jul./dez. 2017. ISSN 2236-0999 (versão eletrônica) 
(8a) There were people sick. - sick $=$ SLP

(8b) ${ }^{\star}$ There were people tall. - tall = ILP

(8c) ${ }^{\star}$ There were cakes tasty. - tasty $=$ PGP

Segundo a autora, apenas a sentença em (8a), que apresenta um SLP, é gramatical em inglês, enquanto (8b), que apresenta um ILP não é possível. Quando colocamos um PGP na mesma estrutura, como em (8c), vemos que a sentença se comporta da mesma forma que a sentença em (8b), ou seja, que o predicado de gosto tasty se comporta como tall, que é um ILP. No entanto, se tentamos traduzir esses exemplos para o $\mathrm{PB}$, nenhuma sentença fica agramatical:

(9a) Tinha pessoas doentes. - doente $=$ SLP

(9b) Tinha pessoas altas. - alto $=$ ILP

(9c) Tinha bolos gostosos. - gostoso $=$ PGP

O que torna o teste eficiente em inglês é o fato de que os adjetivos nessa língua são posicionados antes dos substantivos, deixando claro que, nas sentenças apresentadas em (8), sick, tall e tasty não estão funcionando como adjetivos; em $\mathrm{PB}$, isso se perde, porque tanto os adjetivos quanto as small clauses aparecem após o substantivo. Algo paralelo ocorre com outro teste apresentado pela autora: a combinação de PGPs como small clauses do verbo "ver" (to see):

(10a) John has seen Mary sick.

(10b) `John has seen Mary tall.

138 (10c) `John has seen the cake tasty.

(11a) João viu a Maria doente.

(11b) ? João viu a Maria alta.

(11c) João viu o bolo gostoso.

Novamente, em (11c), não é possível identificar se "gostoso" está funcionando como um adjetivo que caracteriza diretamente "o bolo", ou se está funcionando como uma small clause, o que faz com que o teste não funcione para os dados do PB.

Por fim, outro problema encontrado na passagem dos dados do inglês para o PB é o fato de que todas as sentenças apresentadas por Pearson (2012) em seus testes contêm o verbo to be, para o qual temos dois correspondentes em português: "ser" e "estar". Assim, uma sentença como "This cake is tasty" tem duas traduções possíveis em PB:

(12a) Esse bolo é gostoso.

(12b) Esse bolo está gostoso. 
M. N. Marques

\& R. M. BAsso Predicados de gosto pessoal em português brasileiro: individual ou stage level predicates?
A possibilidade de se traduzir o verbo to be tanto para "ser" quanto para "estar" tem dois impactos para o estudo dos PGPs em português brasileiro. O primeiro é que essa dupla possibilidade de tradução atrapalha a passagem dos testes propostos por Pearson (2012) para o inglês, já que cada sentença trazida pela autora tem agora duas correspondentes em português, e essas duas versões do que seria a mesma sentença em inglês não se comportam de maneira semelhante entre si. A outra influência que tal fato tem sobre o trabalho com os PGPs em $\mathrm{PB}$ é a de que isso pode indicar que esses itens não são, de fato, ILPs como a autora propôs em seu trabalho. Tendo em vista que, na literatura, o verbo "ser" é geralmente associado aos ILPs, enquanto o verbo "estar" seria associado aos SLPs (MARÍN, 2010), é possível argumentar que, caso PGPs como "gostoso" fossem, de fato, ILPs, seria de se esperar que eles não pudessem se combinar com o verbo "estar" e, no entanto, a sentença em (12b) é perfeitamente gramatical. Esse problema será explorado na próxima seção.

\section{Predicados de gosto pessoal são individual level predicates em português brasileiro?}

Como já dito na seção anterior, a possibilidade de combinar os PGPs tanto com o verbo de cópula "ser" quanto com o "estar" pode indicar que esses itens não são, de fato, ILPs como Pearson (2012) defende. Duas possibilidades alternativas de classificação desses predicados trazidas na literatura são: (a) PGPs são, de fato, ILPs, e se combinam com "estar" por coerção (seção 2.1), ou (b) PGPs funcionam tanto como ILPs quanto como SLPs (MARÍN, 2010) (seção 2.2). Feito isso, na seção 2.3 , voltaremos a essa problemática a partir de outra perspectiva.

\subsection{Predicados de gosto são ILPs e se combinam com "estar" por coerção}

A coerção é, em linhas gerais, um processo pelo qual uma sentença que, em princípio, não faria sentido é reinterpretada pelo ouvinte e adquire um novo sentido que a torna aceitável. Esse processo se daria pela eliminação dos conflitos entre o conteúdo semântico de um constituinte e as exigências da construção na qual se encontra esse constituinte. Segundo Marín (2010), ILPs no espanhol podem aparecer combinados com estar, mas a interpretação final da sentença se daria por coerção. Podemos ilustrar isso com dados do PB: (13a), com um ILP, seria possível porque o ILP "britânico", ao se combinar com o verbo "estar"
Revista Letras,

Curitiba, UFPR, n. 96, pp.132-151, jul./dez. 2017. ISSN 2236-0999 (versão eletrônica) 
(tipicamente relacionado a SLPs) é reinterpretado pelo ouvinte como um SLP. Vale notar, ainda, que "britânico" funciona na sentença (13a) porque pode se referir a alguns estereótipos relacionados a essa nacionalidade, como tomar chá, agir educadamente etc., o que explica também por que (13b) não é possível, já que o ILP "surinamês" não traz à tona nenhuma outra referência que não a própria nacionalidade do indivíduo:

(13a) Você está muito britânico (ultimamente).

(13b) \#Você está muito surinamês (ultimamente).

Como indica Marín (2010), a presença de advérbios como "ultimamente" torna a combinação dos ILPs com o "estar" ainda mais aceitável, o que reforça a ideia de que se está interpretando o predicado como um SLP, pois esses advérbios não conseguiriam se combinar com um ILP, já estes predicados são características não-passageiras, ao contrário dos SLPs.

No entanto, não parece ser por coerção que um PGP como "gostoso" se combina com "estar". Considerando uma situação em que uma pessoa fale sobre um bolo em uma festa, apontando para esse bolo e proferindo (14), vemos que "gostoso" não traz nenhum tipo de sentido diferente, como é o caso de "britânico" no exemplo (13a).

(14) Esse bolo está gostoso.

Além disso, se adicionamos um advérbio como "ultimamente" na sentença (14), isso não torna a sentença mais aceitável no contexto apresentado acima, pelo contrário:

(15) ? Esse bolo está gostoso ultimamente.

Em suma, a interpretação de sentenças que combinam PGPs e o verbo "estar" não parece ocorrer por meio de coerção, algo que seria esperado se PGPs fossem, de fato, ILPs. Esse parece ser um argumento contra a afirmação de Pearson (2012) de que PGPs são ILPs. Marín (2010), porém, classifica os adjetivos do espanhol "bonito" (bonito) e "feo" (feio) como predicados ambivalentes, ou seja, que se comportam tanto como ILPs quanto como SLPs e, assim, se combinam tanto com o verbo "ser" quanto com o verbo "estar". Essa saída é analisada com mais cuidado a seguir.

\subsection{Predicados de gosto são tanto ILPs como SLPs}

Marín (2010) classifica os adjetivos "bonito" e "feo" do espanhol como predicados ambivalentes, ou seja, que se combinam tanto com o verbo "ser" 
M. N. Marques

$\&$ R. M. BASSO Predicados de gosto pessoal em português brasileiro: individual ou stage level predicates? quanto com o "estar". Como "bonito" e "feio" são adjetivos que são usados relativamente a quem julga o argumento bonito ou feio, podem ser considerados predicados de gosto pessoal e, portanto, se seguíssemos a categorização de Marín (2010), seria de se esperar que todos os PGPs se comportassem da mesma forma e fossem considerados predicados ambivalentes. $\mathrm{O}$ autor apresenta testes para mostrar em que construções poderiam aparecer os ILPs e os SLPs, e de que forma eles se comportariam em cada uma delas. Os predicados "bonito" e "feo", considerados aqui por nós como PGPs, são classificados pelo autor como predicados ambivalentes do tipo viejo ("velho"), ou seja, que se comportam como o predicado viejo; isso quer dizer que tais itens não são verdadeiramente ambivalentes, porque não conseguiriam aparecer em todos os contextos nos quais um SLP consegue aparecer, e conseguem se combinar apenas com "ser" e "estar".

No entanto, embora os testes de Marín (2010) possam ser adaptados do espanhol para o $\mathrm{PB}$, as leituras levantadas pelas sentenças desses testes não encontra correspondência nas versões traduzidas e, assim, em PB, adjetivos como "bonito" e "feio" não parecem se comportar como seus correspondentes em espanhol, e podem aparecer em todos os contextos nos quais SLPs aparecem. Três das situações trazidas por Marín (2010) como contextos em que um adjetivo do tipo viejo não pode aparecer são: (i) combinados com verbos pseudo-copulares, como "andar", do espanhol e do PB; (ii) como adjuntos predicativos; e (iii) combinados com o verbo "dejar" ("deixar"). Trazemos exemplos das situações (i), (ii) e (iii), respectivamente, em (16):

(16a) *María anda bonita.

Maria anda bonita.

(16b) `Llegó a su casa feo.

Chegou à sua casa feio.

(16c) ${ }^{\star}$ Dejé la chica bonita.

Deixei a menina bonita.

Vemos, no entanto, que essas mesmas sentenças, traduzidas para o PB, não são agramaticais, conforme os exemplos em (17):

(17a) Depois que começou a se maquiar, Maria anda bonita.

(17b) Tomou uma chuva no caminho e chegou à sua casa feio.

(17c) Fiz o cabelo e as unhas dela e deixei a menina bonita. ${ }^{3}$

Dessa forma, os testes elaborados por Marín para o espanhol - que, como o PB, é uma língua que apresenta a diferença "ser”/“estar" - para lidar com os PGPs não são tão seguros e, assim, também não se pode a partir deles classificá3 Os contextos adicionados antes das sentenças propriamente ditas são colocados neste trabalho para que fique mais claro que os exemplos são, de fato, possíveis em PB. No entanto, Marín (2010) não contextualiza as sentenças que ele considera ruins em espanhol em seu trabalho, e apenas diz que elas não são possíveis nessa língua, conforme os exemplos em (16).
Revista Letras,

Curitiba, UFPR, n. 96, pp.132-151, jul./dez. 2017. ISSN 2236-0999 (versão eletrônica) 
los como ILPs ou SLPs. Na próxima seção trazemos, por fim, uma proposta de como podem ser classificados os PGPs segundo dados do PB.

\subsection{Predicados de gosto pessoal são individual level?}

Como vimos nas seções 2.1 e 2.2, não é possível, a partir dos testes pensados para o inglês (PEARSON, 2012) e o espanhol (MARÍN, 2010), classificar os PGPs do PB em ILPs ou SLPs. No entanto, se levamos em conta a definição de ILPs, i.e., predicados que se referem a características inerentes ao sujeito com o qual se combinam, em contraste com a definição de SLPs, que se referem a características transitórias de seu argumento (CHIERCHIA, 1995), parece haver uma maior proximidade entre os PGPs e os ILPs do que entre aqueles e os SLPs, ainda que de um ponto de vista mais conceitual.

Para Marín (2010), SLPs se referem a estados que são, de fato, estados, ou seja, que são o caso num determinado período de tempo. Já ILPs se referem a estados aos quais se aplica a seguinte inferência: se um estado está ocorrendo em um tempo $t$, e não há informação para que se saiba se ele continua ocorrendo num tempo $t^{\prime}$ futuro ou passado, então se infere que ele continua ocorrendo nesse outro tempo t' também - essa inferência é chamada por Marín (2010) de "inferência de persistência temporal". Considerando novamente a sentença "Esse bolo é gostoso", que contém o PGP "gostoso", vemos que o fato de o bolo ser gostoso é algo ao qual se aplica a inferência de persistência temporal; se alguém diz "esse bolo é/está gostoso", não se espera que o bolo vá deixar de ser gostoso, mas sim vai se ter a impressão de que o bolo continuará tendo a propriedade de ser gostoso, a não ser que se informe o contrário em algum momento no futuro ${ }^{4}$.

Para reforçar a ideia de que PGPs são, de fato, ILPs, trazemos um teste adaptado de Chierchia (1995). Para o autor, é impossível modificar esses predicados com locativos, mas é perfeitamente possível modificar SLPs com esses itens, como mostrado nos exemplos em (18) (CHIERCHIA, 1995, p. 178):

(18a) ?? John is intelligent in France.

?? João é inteligente na França.

(18b) John is always sick in France.

João está sempre doente na França.

A sentença em (18a) é estranha porque traz um ILP (intelligent, inteligente), enquanto a sentença em (18b) é aceitável porque seu predicado é um SLP

4 Caso o bolo deixe de ser gostoso para um dado falante, o que temos é (i) o falante mudou seu gosto e/ou (ii) o bolo estragou. Nos dois casos, a propriedade de ser gostoso se aplicou ao bolo durante todo o tempo em que nem (i) ou (ii) ocorreram, ou seja, ou mudou-se o gosto do sujeito (e toda a avaliação tem que ser refeita) ou o bolo perdeu propriedades mais essenciais do que ser gostoso (estragou, por exemplo). As duas situações não invalidam o predicado 'gostoso' de ser um ILP; considerações semelhantes valem, mutatis mutandis, para predicados como 'divertido'. 
M. N. Marques

$\&$ R. M. BASSO Predicados de gosto pessoal em português brasileiro: individual ou stage level predicates? (sick, doente $)^{5}$. Nas traduções para o PB, vemos que o mesmo paralelo pode ser encontrado. Da mesma forma que ocorre em (18a), quando usamos o PGP "gostoso" numa sentença com locativo, a sentença parece estranha:

(19a) ? Esse bolo é gostoso em casa.

(19b) ? Esse bolo está gostoso em casa.

Se considerarmos que PGPs são ILPs, concluiremos que o verbo de cópula usado não muda a classificação desse predicado. Assim, faz sentido que ambas as sentenças em (19) se comportem de modo semelhante e não sejam aceitáveis, embora apresentem verbos de ligação diferentes.

Outro teste que podemos trazer para tratar dos dados do PB já havia sido apresentado por Pearson (2012), que seria o teste dos plurais nus, retirado pela autora também do texto de Chierchia (1995). Esse teste diz que quando ILPs tomam plurais nus como argumentos, a interpretação da sentença é genérica, enquanto no caso de os plurais nus serem argumentos de um SLP, a interpretação é existencial, como podemos observar abaixo (CHIERCHIA, 1995, p. 179):

(20a) Humans are mammals.

Humanos são mamíferos.

(20b) Firemen are available.

Bombeiros estão disponíveis.

Assim, (20a), que apresenta o ILP "mammal”, tem uma leitura genérica, ou seja, poderia ter como uma paráfrase "todos os seres humanos, no geral, são mamíferos”, enquanto (20b), que apresenta o SLP “available”, não levanta essa leitura universal, mas sim uma leitura existencial, e pode ser interpretada como algo nas linhas de "existem (alguns) bombeiros que estão disponíveis".

O problema na passagem desse teste de Pearson (2012) para o PB foi o uso do plural nu, que não muito é muito usual nessa língua para falar algo como a sentença em (20a). No lugar de usar o plural nu, propomos, então, fazer o teste em PB usando o singular nu, e a sentença em (20a) traduzida nesse molde ficaria, então, da seguinte forma:

(21) Humano é mamífero.

De modo paralelo, quando dizemos algo como a sentença em (22), a interpretação dada à sentença é a de que todos os iogurtes do mundo são gostosos, ou seja, a leitura é genérica e universal, assim como em (21):

5 Como apontado por parecerista anônimo, é possível também traduzir "John is sick" como "João é doente". Nesse caso, no entanto, o predicado "doente" muda de sentido; como o sentido pretendido na sentença (18b) é o de "enfermo", apenas o verbo "estar" é possível na tradução.
Revista Letras,

Curitiba, UFPR, n. 96, pp.132-151, jul./dez. 2017. ISSN 2236-0999 (versão eletrônica) 
Assim, dadas as informações que trouxemos nesta seção, vemos que PGPs se comportam de fato como ILPs e, portanto, podem ser categorizados como tal, assim como Pearson (2012) havia argumentado.

Entretanto, ainda fica pendente uma questão: se esses predicados são, de fato, ILPs, por que eles podem se combinar com o verbo "estar"? E por que sentenças que contêm PGPs e que são idênticas a não ser pelo verbo de ligação ("ser" ou "estar") como aquelas em (12a) e (12b) se comportam de maneira diferente e levantam leituras diferentes? Essas questões são o tema da seção seguinte.

\section{O papel do verbo de ligação nas sentenças contendo PGPs}

Argumentaremos neste trabalho que a combinação de PGPs com 'ser' ou com 'estar' parece indicar o tipo de indivíduo tomado pelo predicado, e não a classificação do predicado em SLP ou ILP, como é difundido na literatura. Antes de seguir com esse raciocínio, porém, é necessário que expliquemos o que estamos considerando como tipos possíveis de indivíduo tomados pelos PGPs. A distinção que fazemos desses tipos é se esses indivíduos se referem a conjuntos/ espécies/kinds de itens no mundo (types) ou se denotam ocorrências individuais desses conjuntos/espécies/kinds (tokens). Uma expressão como "esse bolo" pode

144 denotar, por exemplo, uma espécie de bolo - bolo de cenoura, bolo de laranja, os bolos vendidos em determinada padaria - ou então uma ocorrência/instanciação, um bolo específico para o qual se aponta. Assim, o que propomos é que a escolha do verbo de cópula 'ser' ou 'estar' pode indicar o tipo de indivíduo tomado pelo predicado, ou seja, se o argumento do PGP é uma espécie genérica ou uma ocorrência individualizada.

Para visualizar melhor essa proposta, consideremos as sentenças em (23):

(23a) Bolo de laranja é ruim, mas esse (bolo de laranja) é gostoso.

(23b) Bolo de laranja é ruim, mas esse (bolo de laranja) está gostoso.

As duas sentenças são possíveis em PB, e apresentam interpretações um pouco diferentes. Em (23a), o falante parece falar de uma subespécie específica da espécie bolos de laranja, por exemplo, os bolos de laranja feitos por sua mãe. Caso o falante estivesse se referindo a um único bolo de laranja que ele gostou no mundo, intuitivamente, ele proferiria a sentença em (23b) - que apresenta o verbo "estar". De fato, em qualquer situação que consideramos para o proferimento de uma sentença que combina o PGP com "ser" - como na segunda parte de (23a) - parece que o sujeito (no caso, "esse bolo de laranja") se refere a uma espécie, e 
M. N. Marques

$\&$ R. M. BASSO Predicados de gosto pessoal em português brasileiro: individual ou stage level predicates? não a uma ocorrência de bolo. Essa leitura fica ainda mais clara se consideramos uma situação como a seguinte: uma pessoa abre um pacote de bolachas, sendo que não há variação de sabor nem de forma nessas bolachas — elas são idênticas. A pessoa tira duas bolachas do (mesmo) pacote e, então, pode proferir sobre cada uma das bolachas separadamente as seguintes possibilidades de sentença:

(24a) \# Essa bolacha é gostosa, mas essa não é gostosa.

(24b) Essa bolacha está gostosa, mas essa não está gostosa.

Se as bolachas são idênticas, parece estranho que se profira a sentença em (24a). No entanto, uma sentença como aquela em (24b), proferida na mesma situação, parece funcionar bem. O que muda entre as sentenças (24a) e (24b) é justamente o verbo de ligação utilizado para cada uma. Assim, vemos que quando o verbo de cópula usado junto com o PGP é "ser", como em (23a) e (24a), o argumento tomado pelo PGP parece ser sempre do tipo espécie.

Quando se usa o PGP com o verbo "estar", no entanto, a sentença pode apresentar duas leituras distintas: a de que o indivíduo caracterizado é uma espécie, ou então que o indivíduo caracterizado é uma ocorrência única. Em (24b), fica claro que "gostosa" caracteriza uma ocorrência única de bolacha, como já argumentamos acima. Em (23b), no entanto, é possível que, na segunda parte da sentença ("mas esse bolo de laranja está gostoso"), o sujeito ("esse bolo de laranja”) seja tanto uma ocorrência quanto uma espécie.

Para o primeiro caso, podemos considerar uma situação na qual o falante notoriamente odeia bolos de laranja, mas é obrigado a comer um porque sua mãe assou um bolo de laranja e fez chantagem emocional para que ele experimente o que ela preparou. Surpreendentemente, o falante gosta do bolo de laranja - é o único que ele já gostou na vida, e provavelmente o único que ele vai gostar. Ele, então, profere a sentença em (23b).

Para o segundo caso, que diz respeito a situações em que o PGP caracteriza um sujeito do tipo espécie, mesmo combinado com o verbo "estar", trazemos os seguintes exemplos:

(25a) Eu não gostava, mas depois que mudaram a fórmula, Danone está gostoso.

(25b) Esse bolo de laranja está gostoso ultimamente.

(25c) Eu não gostava quando era mais nova, mas agora que eu sou idosa, jiló está gostoso.

Em (25a), o falante não se refere a um pote de iogurte específico, mas à espécie de iogurtes da marca Danone, como o uso do nome próprio já sugere. Em (25b), a presença do 'ultimamente' na sentença corrobora a ideia de que o sujeito "esse bolo de laranja" é uma espécie, pois parece implicar que o falante
Revista Letras,

Curitiba, UfPR, n. 96, pp.132-151, jul./dez. 2017. ISSN 2236-0999 (versão eletrônica) 
não achava o bolo de laranja do qual ele fala gostoso no passado e que, agora, essa opinião mudou. Se há esse intervalo de tempo trazido pelo 'ultimamente', não é possível que ele esteja falando de um único bolo individual. Por fim, a sentença “jiló está gostoso" em (25c) tem como sujeito um singular nu, uma construção que, por si só, já denota indivíduos do tipo espécie em português brasileiro. Dado que essa sentença é possível em PB, e o singular nu "jiló" consegue se combinar com o verbo "estar", isso mostra que é possível que o "estar" tome como argumento um indivíduo do tipo espécie.

Podemos resumir o tipo de argumento tomado por cada estrutura na seguinte tabela:

\begin{tabular}{|c|c|c|}
\hline \multirow{2}{*}{ Tipo de argumento } & \multicolumn{2}{|c|}{ Estrutura } \\
\cline { 2 - 3 } & ser + PGP & estar + PGP \\
\hline espécie & $\operatorname{sim}$ & $\operatorname{sim}$ \\
\hline ocorrência & não & $\operatorname{sim}$ \\
\hline
\end{tabular}

No entanto, olhando para as sentenças em (23) novamente, vemos que embora o indivíduo caracterizado nas segundas partes das sentenças ("esse bolo de laranja é/está gostoso") seja do tipo espécie, o que é possível de acordo com o que acabamos de argumentar, as interpretações das sentenças com os verbos de ligação distintos são diferentes.

Assim, argumentamos que o que diferencia "esse bolo de laranja é gostoso" e "esse bolo de laranja está gostoso" - considerando que o sujeito "esse bolo de laranja” seja do tipo espécie nas duas sentenças - é o fato de que a sentença com o verbo "estar" parece selecionar subespécies no eixo do tempo, o que não ocorre com a sentença com o "ser". Ou seja, quando o falante profere a sentença (23b), ele parece dizer que determinada espécie de bolo de laranja (por exemplo, da loja de bolos x) não era gostosa no passado, mas agora está gostosa, selecionando, assim, um subconjunto dos bolos de laranja dessa espécie que pertencem ao presente, em oposição àqueles que pertencem ao passado ou ao futuro.

Essa interpretação parece, ainda, ser resultado de uma implicatura, pois pode ser cancelada (LEVINSON, 2009):

(26a) Esse bolo de laranja está gostoso... bom, na verdade, ele sempre foi gostoso.

(26b) Danone está gostoso... bom, na verdade, Danone sempre foi gostoso.

Argumentamos, ainda, que essa implicatura tem relação com a máxima de quantidade de Grice: "faça com que sua contribuição seja tão informativa quanto solicitado (requerido) (para o propósito corrente da conversação)” (PIRES DE OLIVEIRA; BASSO, 2014, p. 77). Para ilustrar essa máxima, comparemos as seguintes sentenças: 
M. N. Marques

$\&$ R. M. BASSO Predicados de gosto pessoal em português brasileiro: individual ou stage level predicates? (27a) Alguns alunos passaram no exame.

(27b) Todos os alunos passaram no exame.

De acordo com Pires de Oliveira e Basso (2014), há duas situações nas quais a sentença em (27a) é verdadeira. Os autores ilustram essas situações nos seguintes diagramas:

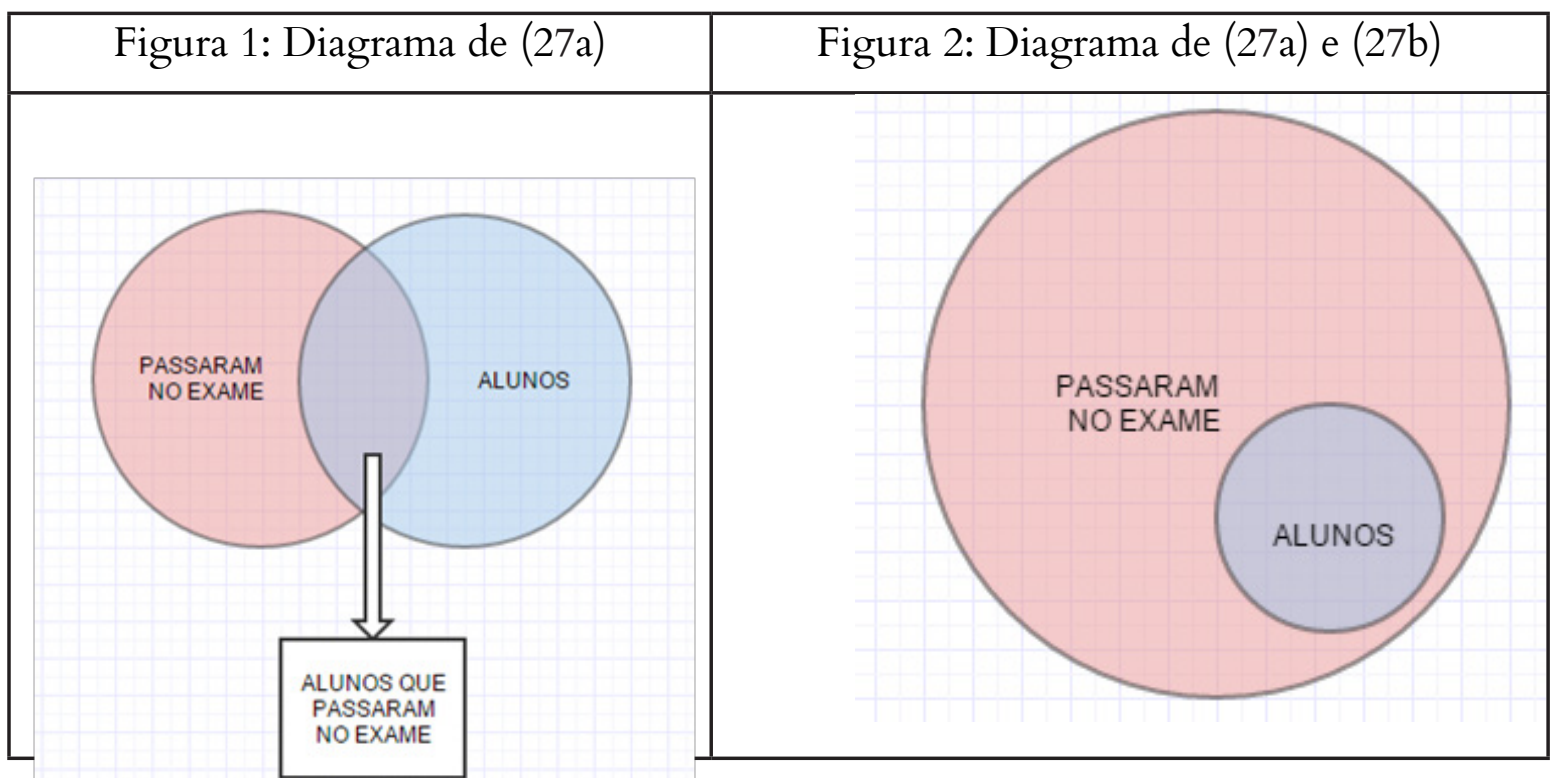

No entanto, (27a) implica a situação mostrada na Figura 1. Isto é, se alguém profere "alguns alunos passaram no exame", intuitivamente, se entende que nem todos os alunos passaram no exame. Isso ocorre porque o interlocutor assumirá que o falante está seguindo essa máxima de quantidade proposta por Grice e, portanto, está fazendo de seu proferimento o mais informativo possível dentro do que é necessário para a conversa. (27b), diferentemente de (27a), só pode ser verdadeira na situação da Figura 2. Portanto, se há uma maneira mais informativa de dizer ao interlocutor que a situação é correspondente ao que se representa na Figura 2, então o interlocutor irá inferir que quando o falante profere (23a), ele indica a situação da Figura 1, e não da Figura 2, que poderia ser mais precisamente retratada pela sentença (27b).

Consideremos, agora, que as sentenças em (28) dizem respeito a situações nas quais o falante não gosta de bolo de laranja no geral, mas gosta daqueles feitos pela sua mãe, i.e., uma subespécie dos bolos de laranja; consideramos também os gráficos representativos dessas sentenças.

(28a) Esse bolo de laranja é gostoso.

(28b) Esse bolo de laranja está gostoso. 


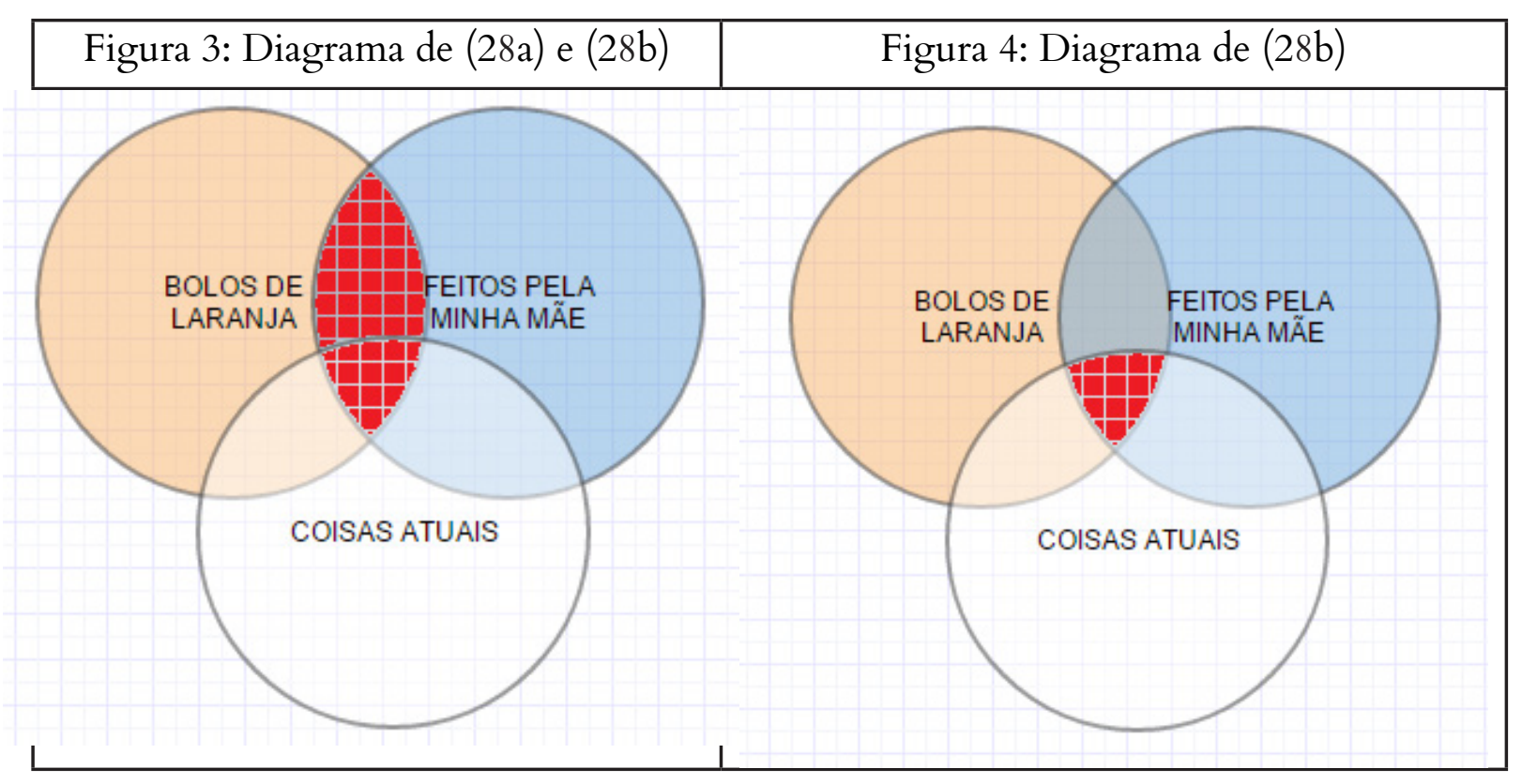

Com esses dados em vista, vemos que há um paralelo entre a implicatura relacionada à máxima de quantidade apresentada por Pires de Oliveira e Basso (2014) e a implicatura de que os PGPs combinados ao verbo "estar" selecionam subconjuntos relacionados ao tempo. Assim como no caso das sentenças em (27), há uma figura que representa as duas situações (Figura 3) e uma que se corresponde a apenas à situação da sentença em (28b) (Figura 4). Se a sentença em (28b) é verdadeira nas duas situações representadas pelas figuras, então quando o falante quer se referir à situação representada na Figura 3, ele deveria, pela máxima de quantidade, proferir (28a), já que, em comparação com (28b), ela é mais informativa, pois é verdadeira em apenas um caso. Assim, quando o falante profere (28b), fica implícito que ele se refere à situação da Figura 4, ou seja, que apenas os bolos de laranja atuais de sua mãe são gostosos, pois se esse não fosse o caso, ele proferiria a sentença com maior quantidade de informações relevantes ((28a)).

Poderia ser argumentado, já que é o caso que se está falando de uma subespécie no eixo do tempo, que o PGP se comporta como um SLP nessa situação e, portanto, que PGPs não são ILPs, mas sim predicados ambivalentes, uma hipótese que já havíamos descartado na seção anterior. No entanto, mesmo nessas situações, os PGPs não se comportam da mesma forma que os SLPs, como podemos ver comparando as sentenças em (29), que contêm, respectivamente, o PGP "gostoso" e o SLP “em extinção":

(29a) Bolo de laranja está gostoso... bom, na verdade, bolo de laranja sempre foi gostoso. ${ }^{6}$

(29b) ?? Baleia está em extinção... bom, na verdade, baleia sempre foi em extinção.

6 Conforme parecerista anônimo, a primeira parte da sentença em (29a), "Bolo de laranja está gostoso”, parece estranha por não trazer um determinante. Argumentamos, entretanto, que é possível proferir essa sentença sem o determinante, caso consideremos que, nessa sentença, "bolo de laranja" se refere a uma espécie (tomada no eixo do tempo, funcionando da mesma forma que o exemplo em (25c)). 
M. N. Marques

\& R. M. Basso Predicados de gosto pessoal em português brasileiro: individual ou stage level predicates?
Há em (29a) uma leitura de que bolos de laranja não eram gostosos no passado, mas são gostosos apenas no presente. Essa leitura pode ser cancelada com a continuação proposta, o que indica que essa interpretação se trata de uma implicatura. No entanto, em (29b), não podemos cancelar da mesma forma a leitura de que as baleias estão em extinção apenas no presente, como fizemos em (29a). Assim, é possível notar que em (29a), o predicado pode denotar algo inerente da espécie bolo de laranja, mesmo que a primeira interpretação seja a de que é uma característica apenas momentânea desses bolos, o que não pode ser o caso de (29b), cuja presença do SLP "em extinção" faz com que a única leitura que possamos ter da sentença seja a de que a espécie "baleia" tem essa característica (de estar em extinção) apenas no presente, e que não é possível que isso seja algo inerente a ela.

\section{Considerações finais}

O tema central deste trabalho foram os predicados de gosto pessoal, considerando com mais foco o problema da classificação desses predicados em individual ou stage level. Esse problema, como falamos na seção 1, é algo que foi levantado a partir da análise de Pearson (2012), que propõe uma formalização para os PGPs que envolve um operador genérico GEN, em paralelo ao que Chierchia (1995) apresenta para a formalização dos ILPs. Para que isso seja possível, a autora argumenta que PGPs são ILPs e, portanto, que podem ser formalizados nas mesmas linhas de Chierchia (1995), dedicando uma boa parte de seu trabalho para defender sua teoria. No entanto, como já citado, os testes propostos por Pearson (2012) para fazer a relação entre PGPs e ILPs não funcionam se os reproduzimos com dados do $\mathrm{PB}$, muitas vezes por falta de correspondência entre as estruturas das duas línguas. Além disso, a autora desconsidera a diferença entre "ser" e "estar" que aparece em PB na tradução do verbo to be do inglês, que, como mostramos, é algo que é relevante para a discussão que diz respeito à classificação dos PGPs em ILPs ou SLPs.

Em seguida, na seção 2, mostramos outras possibilidades de classificação dos PGPs de acordo com a literatura, que são (i) ILPs que se combinam com "estar" por coerção ou (ii) predicados ambivalentes, i.e., que funcionam como ILPs e SLPs ao mesmo tempo. No entanto, concluímos que essas possibilidades não são satisfatórias, e argumentamos (nocionalmente e também com base em alguns testes linguísticos) que Pearson (2012) de fato estava certa quando afirmou que PGPs são ILPs, mesmo que esses predicados possam se combinar com o verbo "estar", relacionado aos SLPs e não aos ILPs.
Revista Letras,

Curitiba, UFPR, n. 96, pp.132-151,

jul./dez. 2017. ISSN 2236-0999 (versão eletrônica) 
Assim, foi necessário explicar por que tanto o verbo "ser" quanto o "estar" podem ser combinados com PGPs, já que estes foram classificados como ILPs. $\mathrm{Na}$ seção 3, então, afirmamos que o papel do verbo de ligação nas sentenças que trazem os PGPs não é o de indicar o tipo de predicado, mas sim o tipo de argumento tomado pelo predicado, i.e., se o argumento denota (sub)espécies ou se ele denota ocorrências de determinada espécie. Dessa forma, o PGP seria sempre ILP, independentemente do verbo de ligação com o qual ele se combina, e a diferença de interpretação entre sentenças que contêm PGPs e são idênticas a não ser pelo verbo copular usado ocorreria devido à diferença do tipo de argumento tomado pelo predicado. 
M. N. Marques

$\&$ R. M. BASSO Predicados de gosto pessoal em português brasileiro: individual ou stage level predicates?

\section{Referências Bibliográficas}

CHIERCHIA, G. Individual level-predicates as inherent generics. In: CARLSON, G. N.; PELlETIER, F. J. (Eds.) The Generic Book. Chicago: Universtiy of Chicago Press, 1995. p. 176-223.

FLEISHER, N. The dynamics of subjectivity. In: Proceedings of Semantics and Linguistic Theory (SALT) 23, Santa Cruz, 2013. p. 276-294.

LASERSOHN, P. Context dependence, disagreement, and predicates of personal taste. Linguistics and Philosophy, v. 28, n. 6, p. 643-686, 2005.

LEVINSON, S. C. Conversational implicature. In: Cambridge: Cambridge University Press, 2009. p. 97-166. Pragmatics. 20. ed.

MARÍN, R. Spanish adjectives within bounds. In: CABREDO HOFFHERR, P.; MATUSHANSKY, O. (Eds.). Adjectives: Formal analyses in syntax and semantics. Amsterdã/Filadélfia: John Benjamins Publishing Company, 2010. p. 307-332.

PEARSON, H. A judge-free semantics for predicates of personal taste. Journal of Semantics, v. 30, n. 1, p. 103-154, 2012.

PIRES DE OLIVEIRA, R.; BASSO, R. M. 'Algumas', talvez todas, implicaturas conversacionais generalizadas. In: . Arquitetura da conversação: teoria das implicaturas. São Paulo: Parábola, 2014. p. 69-95.

STEPHENSON, T. C. Towards a theory of subjective meaning. 212f. Tese (Doutorado) - Department of Linguistcs and Philosophy, Massachusetts Institute of Technology. Cambridge, 2007.

Submetido em: 05-03-2017

Aceito em: 25-03-2017
Revista Letras, Curitiba, UFPR, n. 96, pp.132-151, jul./dez. 2017. ISSN 2236-0999 (versão eletrônica) 